\title{
Selective Cytotoxicity and Apoptogenic Activity of Hibiscus Sabdariffa Aqueous Extract against MCF-7 Human Breast Cancer Cell Line
}

\author{
Shahnaz Khaghani ${ }^{1}$, Farideh Razi $^{2}$, Mohsen Mohammadian Yajloo ${ }^{3}$, Malihe Paknejad ${ }^{1,4}$, Ahmad \\ Shariftabrizi ${ }^{1}$, Parvin Pasalar ${ }^{1,2^{*}}$ \\ ${ }^{1}$ Department of Clinical Biochemistry, Faculty of Medicine, Tehran University of Medical Sciences, Tehran, Iran; ${ }^{2}$ Endocrinology \\ and Metabolism Center, Shariati Hospital, Tehran University of Medical Sciences, Tehran, Iran; ${ }^{3}$ Center for Research on Occupa- \\ tional Diseases (GRAD), Tehran University of Medical Sciences, Tehran, Iran; ${ }^{4}$ Students' Scientific Research Center (SSRC), Te- \\ hran University of Medical Sciences, Tehran, Iran. \\ Email: *pasalar@tums.ac.ir
}

Received April $7^{\text {th }}$, 2011; revised June $3^{\text {rd }}$, 2011; accepted June $23^{\text {rd }}, 2011$.

\begin{abstract}
Background: Herbal compounds are attractive anticancer candidates due to their low toxicity. Previous studies have demonstrated that Hibiscus sabdariffa is promising as an anticancer agent against several cancer types; however, its potential therapeutic role in breast cancer remains to be investigated. Materials and Methods: In the present study, the cytotoxic effects of Hibiscus sabdariffa aqueous extract (HSE) on a human breast adenocarcinoma cell line (MCF-7) and fetal foreskin fibroblast (HFFF) were investigated. Different concentrations of water extract of calyces were added and the percentage of cell survival was determined after 24, 48, and 72 hours using an MTT assay. Apoptosis induction was assessed by DNA fragmentation. Results: At the concentration of $0.5 \mathrm{mg} / \mathrm{ml}$ of the extract and following 72 hours of incubation, the number of viable MCF-7 cells was less than 50\%. The extract was not cytotoxic against normal HFFF cells in all tested concentrations. Also, HSE induced apoptosis only in MCF-7 cells. Conclusions: These results suggest that HSE inhibits the growth of MCF-7 cells selectively in a concentration-and time-dependent manner. As this herbal substance has been shown to be nontoxic at very high doses in experimental animals, it might be a good anticancer drug candidate for breast cancer treatment.
\end{abstract}

Keywords: Hibiscus Sabdariffa, Natural Anticancer Compound, MTT Assay, Apoptosis, Breast Cancer

\section{Introduction}

Cancer is a major public health problem in the United States and many other parts of the world, accounting for roughly $25 \%$ of total deaths annually. The three most commonly diagnosed types of cancer among women in 2010 were cancers of the breast, lung, and colorectum, accounting for $52 \%$ of cancer cases in this group. Breast cancer alone accounted for 28\% $(207,090)$ of all new cancer cases among women [1,2].

The toxicity associated with conventional cancer chemotherapy arises primarily from the lack of specificity for tumor cells. This leads to a low therapeutic index, which results in unacceptable damage to normal organs and consequently puts limitations on the dose of the drug that can be administered. The majority of the currently available anticancer drugs are designed to have selective toxicity toward tumor cells $[3,4]$. Several approaches are being considered to handle this problem and thus improve the effectiveness and tumor-cell specificity of anticancer drugs. Among these approaches, many studies have focused on natural compounds that inhibit the growth of cancer cells more selectively than normal cells. Thus, phytochemicals have become an important category of anticancer drugs. Over $75 \%$ of non-biological anticancer drugs approved between 1981 and 2007 were either natural products or were developed based on them [5].

Herbal medicines are usually very easily accepted by women suffering from breast cancer. As many as $80 \%$ of women with breast cancer use some form of complementary or alternative medicine, the most common of which is the use of herbs, in the hope that they might lessen the side effects of treatment, improve quality of 
life, provide a greater sense of control, and reduce stress [6,7]. A beneficial effect of herbal substances in breast cancer treatment is still in doubt mainly due to lack of randomized clinical trials [8]. This is even true for Chinese herbal remedies [9].

Hibiscus sabdariffa (also known as roselle, sour tea, and karkade) from the Malvaceae family is cultivated and naturalized in tropical and subtropical regions, including south of Iran (Baluchestan). The plant has been used in different countries as a culinary and medicinal substance. The fleshy fruiting calyces of this plant, which are sour in taste, have been utilized for preparing candies, jellies, and hot and cold beverages. In folk medicine, the calyx extract of this plant is used for treatment of several illnesses, including high blood pressure, gastrointestinal disorders, hypercholesterolemia, liver diseases, and fever [10-13]. This plant has also been shown to have anticancer effects in vitro against gastric cancer [14,15], hepatocellular cancer [16], and leukemia [17-19]. Hibiscus protocatechuic acid has also been shown to inhibit the carcinogenic effect of various chemicals in different tissues of rats, including the liver, oral cavity, colon, glandular stomach tissue, bladder, and skin [12]. The plant's extract is characterized by a very low degree of toxicity. The $\mathrm{LD}_{50}$ of calyx extract in rats has been found to be above $5000 \mathrm{mg} / \mathrm{kg}$ [12].

Constituents of Hibiscus sabdariffa have been extensively studied since 1932 . The chemicals present in the flowers of Hibiscus sabdariffa include citric and malic acids; tartaric acids; anthocyanins (delphinidinentoside-glucoside, delphinidin-3-glucoxyloside, delphinidin-3-ambubioside, cyanidin-monoglucoside, cyanidin3-sambubioside, cyanidin-3,5-diglucoside, cyanidin-3glucosylrutinoside, cyanidin-3-glucoside); flavonol glycoside; gossypitrin; quercetin; myricetin; hibiscetrin; sabdaretin; quercetin; luteolin, a luteolin glycoside and chlorogenic acid; flavonoids (gossypetin, hibiscetin, and their respective glycosides); protocatechuic acid; and sterols ( $\beta$-sitosterol and ergosterol). Different strains of Hibiscus sabdariffa from different countries may differ in one or several of these constituents [12].

The aim of the present study was to investigate the cytotoxic effect of HSE on a human breast adenocarcinoma cell line (MCF-7) and a human fetal foreskin fibroblast cell line (HFFF) as the benign counterpart.

\section{Materials and Methods}

\subsection{Preparation of Aqueous Extract of Hibiscus Sabdariffa}

Hibiscus sabdariffa calyces were obtained in the traditional market in Tehran, Iran, and authenticated by the
Department of Botany, Tehran University of Medical Sciences. The voucher specimen was deposited in the herbarium of the Tehran University of Medical Sciences. The samples were washed of any contaminants, then dried and crushed. The powdered calyces were subjected to extraction by the maceration method with distilled water at $25^{\circ} \mathrm{C}$ for 48 hours. The extract was filtered using Whatman filter paper and then evaporated to dryness using a rotary evaporator $\left(40^{\circ} \mathrm{C}\right)$. The dried extract was prepared as a stock solution, sterilized, and further diluted to final concentrations of $0.5,0.4,0.3,0.2,0.1$, and $0.05 \mathrm{mg} / \mathrm{ml}$.

\subsection{Cell Culture}

Human breast adenocarcinoma (MCF-7, NCBI C135) and normal human fetal foreskin fibroblast (HFFF, NCBI C170) cell lines, which were obtained from the National Cell Bank of Iran (NCBI), were used in this study. These cell lines were grown in a RPMI-1640 medium (Sigma, USA), supplemented with $10 \%(\mathrm{~V} / \mathrm{V})$ fetal calf serum (FCS) (Seromed, Germany), 1\% of L-glutamine (2 mM) (Sigma), $1 \%$ of sodium pyruvate $(1 \mathrm{mM})$ (Sigma), and $1 \%$ of penicillin/streptomycin (50 IU/ml and $500 \mu \mathrm{g} / \mathrm{ml}$, respectively) (Sigma), according to the manufacturers' instructions. The cell lines were maintained in a humidified atmosphere of $5 \% \mathrm{CO}_{2}$ at $37^{\circ} \mathrm{C}$. After the expansion of cultures to approximately $75 \%-80 \%$ confluency, cells were trypsinized with $0.25 \%$ trypsin/ $0.04 \%$ EDTA solution in phosphate-buffered saline (PBS) (Sigma) for 1-2 minutes. For cytotoxicity assays, $2.5 \times 10^{4}$ cells/well were cultured in 96-well microplates [9].

\subsection{Cytotoxicity Assay}

The cytotoxic effect of HSE against tumor and normal cell lines was determined by a rapid colorimetric assay using MTT (methyl-thiazolyl-tetrazolium bromide), and results were compared with control [10]. In this assay, mitochondrial dehydrogenase activity of viable cells reduces the soluble MTT into an insoluble colored formazan product, which in turn can be dissolved in DMSO (dimethyl sulfoxide) and measured spectrophotometrically [11]. Briefly, $2.5 \times 10^{4}$ cells/well were seeded in 96 well microplates and incubated for 12 hours $\left(37^{\circ} \mathrm{C}\right.$, humidified air and $5 \% \mathrm{CO}_{2}$ ). Then various concentrations of the extract $(0.5,0.4,0.3,0.2,0.1$ and $0.05 \mathrm{mg} / \mathrm{ml})$ were added, and the microplates were further incubated for 24,48 , and 72 hours in the same conditions. One column of each microplate was used as negative control (containing no extract). To evaluate the cell survival, each well was incubated with $20 \mu \mathrm{l}$ of MTT solution (5 $\mathrm{mg} / \mathrm{ml}$ PBS) for 3 hours, and then $150 \mu \mathrm{l}$ of the media of each well was replaced with DMSO and mixed to dissolve insoluble formazan crystals. Then the absorbance 
of each well was measured spectrophotometrically at 540 $\mathrm{nm}$, and cell survival was calculated. Cytotoxicity was considered significant whenever cell survival percentage was below 50 .

\subsection{DNA Ladder Assay for Apoptosis}

Cultured cells grown on a $100 \mathrm{~mm}$ Petri dish were treated with various concentrations of HSE for 72 hours. The cells were harvested by scraping and then centrifuged at $800 \times \mathrm{g}$ for 10 minutes at $4^{\circ} \mathrm{C}$. The pattern of DNA cleavage was analyzed by agarose gel electrophoresis using a DNA ladder kit (Roche, Germany) according to the manufacturer's instruction. Briefly, cells were first lysed in a solution containing $6 \mathrm{M}$ guanidine- $\mathrm{HCl}$, $10 \mathrm{mM}$ Urea, $10 \mathrm{mM}$ Tris-HCL, 20\% Triton X-100, and $\mathrm{pH}=4.4$, followed by incubation for 10 minutes at $25^{\circ} \mathrm{C}$. Ispropropanol was added to the mixture, filtered, and washed with a buffer containing $20 \mathrm{mM} \mathrm{NaCl}, 2 \mathrm{mM}$ Tris-HCl, and $80 \%$ ethanol. The DNA bound to the filters was finally eluted with a prewarmed elution buffer (10 mM Tris, $\mathrm{pH}=8.5)$. The sample DNA was suspended in TAE buffer (10 mMTris-HCl and 0.5 mMEDTA, pH 8.0) and loaded onto a 1.2\% agarose gel. After electrophoresis, DNA was visualized by ethidium bromide staining.

\subsection{Statistical Analysis}

Statistical analysis was performed using ANOVA and postHOC tukey test using SPSS software. Significant differences were established at $p<0.05$.

\section{Results}

\subsection{Selective Cytotoxic Activity of HSE against MCF-7 and HFFF Cell Lines}

Aqueous extract of Hibiscus sabdariffa appeared to be toxic towards MCF-7 cells in a dose- and time-dependent manner. Each concentration was assayed in eight wells on each plate, and the average was considered as a single experiment. Each experiment was repeated three times. Cell survival was calculated by the following formula: mean of test sample divided by mean of untreated sample (negative control) in which cell survival percent was taken as 100 . Cytotoxicity was considered significant whenever cell survival was less than $50 \%$. The effect of various concentrations and incubation times is depicted in Figures 1(a)-(c). No significant cytotoxic effect was observed in the MCF-7 cell line after 24 hours in all concentrations. There was significant reduction of cell numbers in the MCF-7 cell line following 48 and 72 hours in the doses of $0.4 \mathrm{mg} / \mathrm{ml}$ and above. At a concentration of $0.5 \mathrm{mg} / \mathrm{ml}$ of the extract, following 72 hours of incubation, cell survival was $45.51 \%(p<0.05)$. To determine whether this effect was selective, the extract was also used against a human fetal foreskin fibroblast cell line. The results indicated that unlike cancer cells, the extract was not cytotoxic towards the HFFF cell line after 24 - 72 hours of incubation in all tested concentrations.

\subsection{Apoptogenic Activity of HSE against MCF-7 Cell Line}

Apoptogenic activity of HSE was assayed using a DNA fragmentation method. Nuclear DNA fragmentation is a biochemical hallmark of apoptosis, which shows DNA fragments in multiples of 180 - 200 base pairs on agarose gel, as opposed to the smear formation in necrotic cells. The fragments correspond in size to strands of DNA that were cleaved at internucleosomal regions. These result from activation of Caspase- 3 and endonucleases. Thus, gel electrophoresis was used to determine the mode of death induction in MCF-7 and HFFF cell lines by HSE. At the dose of $0.5 \mathrm{mg} / \mathrm{ml}$ following 72 hours of incubation, clear formation of a DNA ladder was observed (Figure 2). No ladder formation was observed in HFFF cells.

\section{Discussion}

The toxicity associated with cancer chemotherapy arises primarily from the lack of specificity for tumor cells. To handle this problem, the focus of many studies is on natural compounds that inhibit cancer cells more selectively than normal cells. This study was undertaken to demonstrate the effects of HSE on MCF-7 and normal HFFF cell lines. Here, we determined the cytotoxic concentration in which the plant extract significantly inhibited growth of breast cancer cells. The same dose also proved to be apoptogenic for the MCF-7 breast carcinoma cell line.

Although the exact mechanisms of HSE aqueous extract on cancer cells are not known, mechanisms of apoptosis induction in other models have been elucidated. In gastric carcinoma, HSE induces apoptosis by p38 MAPK and JNK activation, and translocation of cytochrome $c$ from the mitochondria to the cytosol and caspase cascade activation [14]. Polyphenol-rich HSE induces apoptosis in gastric carcinoma cells by activation of p38/Jun/FasL signaling and stabilization of p53, causing an increase in Bax and cytochrome c release, leading to the activation of caspase-3 [15]. Delphinidin 3 -sambubioside from Hibiscus induces apoptosis via PARP inactivation; activation of caspase-3, -8 , and -9 ; and generation of reactive oxygen species in leukemia [17]. Hibiscus anthocyanin-rich extract induces apoptosis 


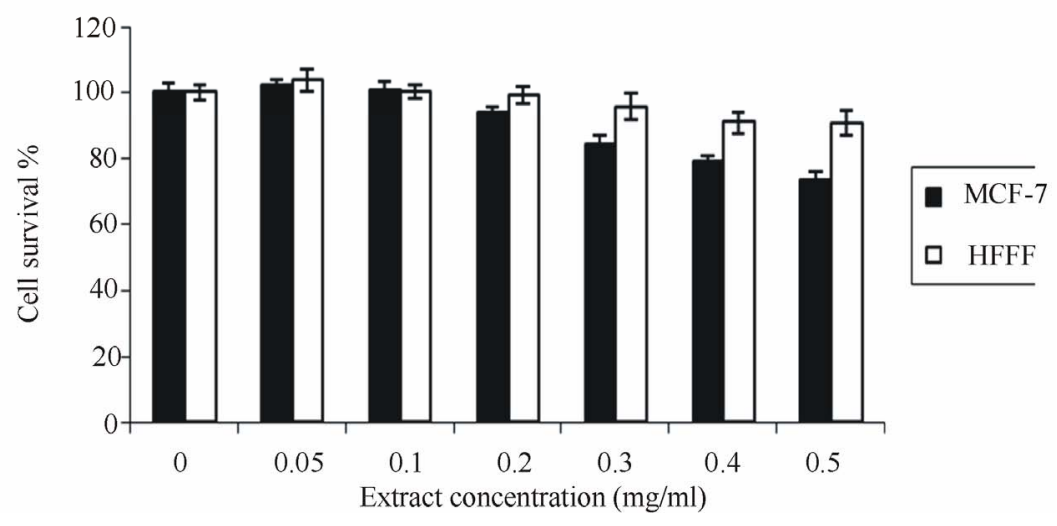

(a)

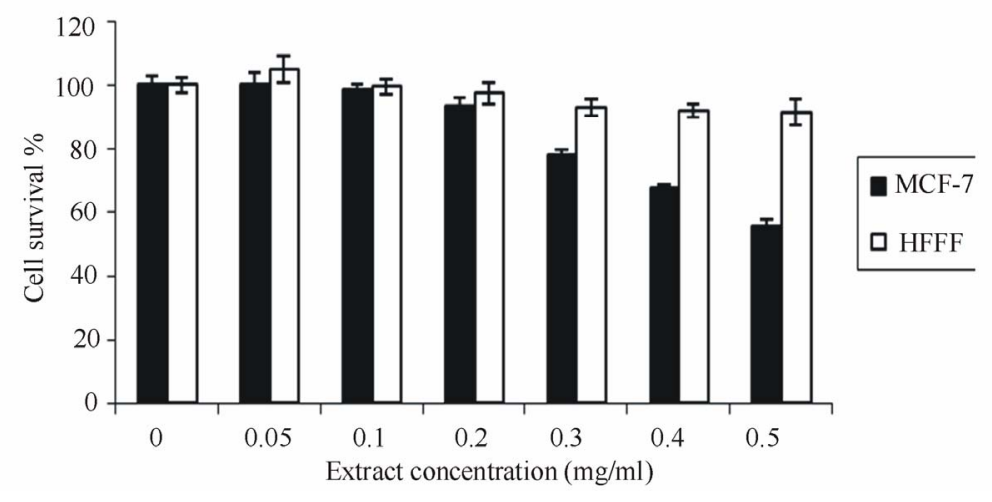

(b)

$72 \mathrm{~h}$

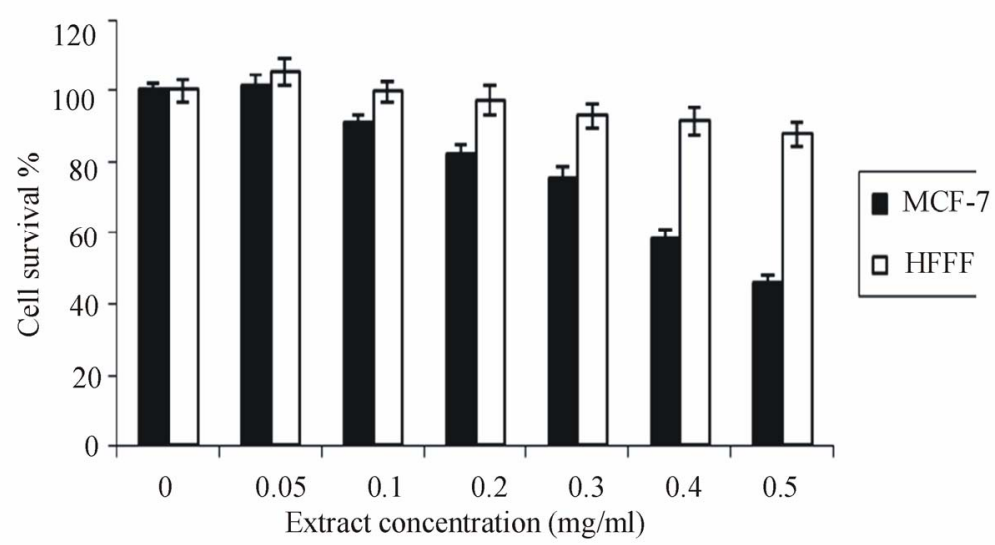

(c)

Figure 1. Selective cytotoxic activity of HSE against MCF-7 and HFFF cell lines. HFFF and MCF-7 cells were seeded, and after 12 hours, increasing doses of HSE extract were added to the media. Cells were harvested after 24, 48, and 72 hours, and cell numbers were analyzed using an MTT assay. No significant cytotoxic effect was observed in the MCF-7 cell line after 24 hours in all concentrations (1-a). There was significant reduction of cell numbers in the MCF-7 cell line following 48 and 72 hours in doses of $0.4 \mathrm{mg} / \mathrm{ml}$ and above (1-b, 1-c). At concentration of $0.5 \mathrm{mg} / \mathrm{ml}$ of the extract and following 72 hours incubation, cell survival was $45.51 \%(p<0.05)(1-c)$. 


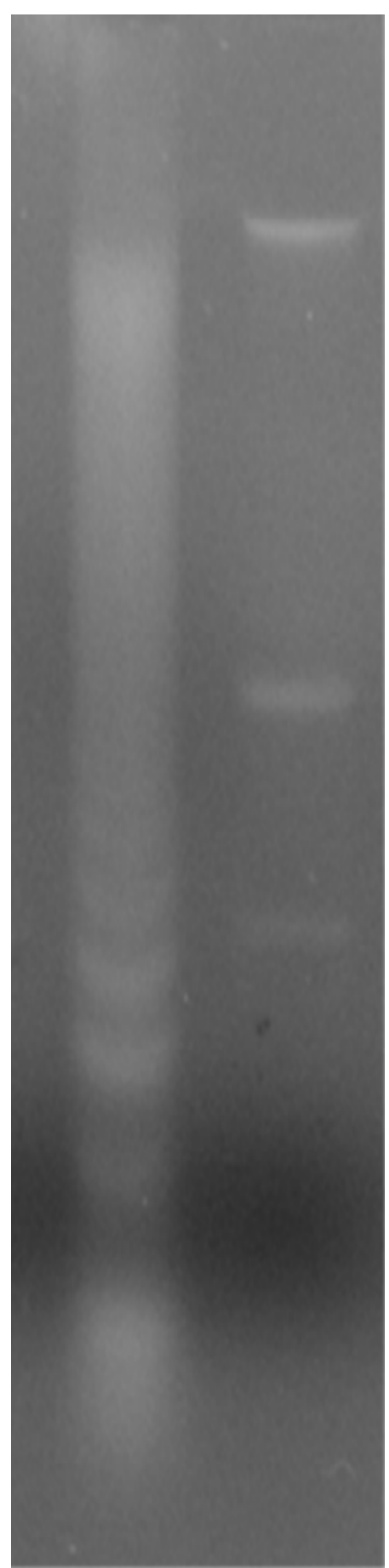

Figure 2. Apoptogenic activity of HSE against MCF-7 and HFFF cell line. To check for DNA fragmentation as a sign of apoptosis, DNA was purified and analyzed on agarose gel. At the dosage of $0.5 \mathrm{mg} / \mathrm{ml}$ following 72 hours of incubation, clear formation of a DNA ladder was observed in the MCF-7 cell line. No ladder formation was observed in HFFF cells.

in promyelocytic leukemia cells by increased phosphorylation of p38 and c-Jun, cytochrome c release, and expression of tBid, Fas, and FasL [18]. Induction of apoptosis by Hibiscus protocatechuic acid in human leu- 
kemia cells via reduction of retinoblastoma phosphorylation and $\mathrm{Bcl}-2$ expression is also reported [19].

Previous investigators have shown that aqueous extract of Hibiscus sabdariffa might contain anthocyanins, polyphenols, and flavonoids [12]. Flavonoids [20], polyphenols [21,22], and anthocyanins [23,24] are all shown to have anticancer effects. Meanwhile, we have not yet specifically looked into the active ingredient(s) of the HSE that inhibits the growth of breast cancer.

Use of inappropriate concentrations of dietary phytochemicals in mechanistic studies may generate artifactual results, which can be misleading and physiologically irrelevant [25]. We have observed cytotoxicity of the crude extract at doses below that reported by other investigators in other cancer cell types [14], which implies that breast cancer is a better model for in vivo studies of HSE because of a more realistic predicted in vivo concentration.

Forty to seventy percent of breast tumors are estrogen receptor positive, and considerable effort has been targeted towards blocking estrogen receptors for treatment and chemoprevention of breast cancer [26]. Phyto- oestrogens were originally proposed as cancer protective agents following epidemiological observations revealing a low breast cancer incidence in soy-consuming populations [27]. There are reports that HSE might have estrogenic effects, although the exact estrogen-like ingredient is not determined [12]. HSE contains at least two phytosterols, $\beta$-sitosterol and ergosterol [12]. Ergosterol has been previously shown to have apoptogenic effect against MCF-7 cell lines [28]. Oral $\beta$-sitosterol markedly reduces E2-induced MCF-7 tumors in mice [29] and lowers serum estrogen levels, suggesting that consumption of phytosterols from HSE may be beneficial for women with breast cancer. We are interested in this aspect of HSE and plan to evaluate its effect on estrogen receptors in breast carcinoma models.

While our results are promising regarding the anticancer effects of a relatively safe substance [12], use of every crude herb is complicated by the lack of data regarding the consumption amount necessary to have the desired effects in vivo.

\section{Conflict of Interest}

There is no conflict of interest with regard to this manuscript.

\section{Acknowledgements}

The authors wish to express their gratitude to Tehran University of Medical Sciences, which provided the funding for this work (Grant Number: 86-01-30-5355).

\section{REFERENCES}

[1] C. Andreetta, A. M. Minisini, M. Miscoria and F. Puglisi, "First-Line Chemotherapy with or without Biologic Agents for Metastatic Breast Cancer," Oncology Hematology, Vol. 76, No. 2, 2010, pp. 99-111. doi:10.1016/j.critrevonc.2010.01.007

[2] A. Jemal, R. Siegel, J. Xu and E. Ward, "Cancer Statistics, 2010,” A Cancer Journal for Clinicians, Vol. 60, No. 5, 2010, pp. 277-300. doi:10.3322/caac.20073

[3] F. Valeriote and L. Putten, "Proliferation Dependent Cytotoxic Action of Anti Cancer Agents: A Review," Cancer Research, Vol. 35, No. 10, 1975, pp. 2619-2630.

[4] M. P. Deonarain and A. A. Epenetos, “Targeting Enzymes for Cancer Therapy: Old Enzymes in New Roles,” British Journal of Cancer, Vol. 70, 1994, pp. 786-794. doi:10.1038/bjc.1994.400

[5] D. J. Newman and G. M. Cragg, "Natural Products as Sources of New Drugs over the Last 25 Years," Journal of National Products, Vol. 70, 2007, pp. 461-477. doi:10.1021/np068054v

[6] H. Roberts, "Safety of Herbal Medicinal Products in Women with Breast Cancer,” Maturitas, Vol. 66, No. 4, 2010, pp. 363-369. doi:10.1016/j.maturitas.2010.02.010

[7] L. Y. Wong, P. C. Leung, J. L. Tang and S. W. Mercer, "Use of Dietary Supplements by Breast Cancer Patients Undergoing Conventional Cancer Treatment," Patient Prefer Adherence, Vol. 4, 2010, pp. 407-414. doi:10.2147/PPA.S13639

[8] E. Ernst, K. Schmidt and M. Baum, "Complementary/Alternative Therapies for the Treatment of Breast Cancer. A Systematic Review of Randomized Clinical Trials and a Critique of Current Terminology," The Breast Journal, Vol. 12, No. 6, 2006, pp. 526-530. doi:10.1111/j.1524-4741.2006.00340.x

[9] S. Fulda, S. A. Susin, G. Kroemer and K. M. Debatin, "Molecular Ordering of Apoptosis Induced by Anticancer Drugs in Neuroblastoma Cells," Cancer Research, Vol. 58, No. 9, 1998, pp. 4453-4460.

[10] T. Mosmann, "Rapid Colorimetric Assay for Cellular Growth and Survival: Application to Proliferation and Cytotoxicity Assays," Journal of Immunological Methods, Vol. 65, No. 1-2, 1983, pp. 55-63. doi:10.1016/0022-1759(83)90303-4

[11] J. Carmichale, W. G. Degraff, A. F. Gazdar, J. D. Minna and J. B. Mitchell, "Evaluation of a Tetrazolium Based Semi-automated Colorimetric Assay: Assessment of Chemo-Sensitivity Testing," Cancer Research, Vol, 47, No. 4, 1987, p. 936.

[12] B. H. Ali, N. Wabel and G. Blunden, "Phytochemical, Pharmacological and Toxicological Aspects of Hibiscus Sabdariffa L.: A Review,” Phytotherapy Research, Vol. 19, No. 5, 2005, pp. 369-375. doi:10.1002/ptr.1628

[13] A. H. Arellanoa, S. F. Romero, M. A. Soto and J. Tortoriello, "Effectiveness and Tolerability of a Standardized Extract from Hibiscus Sabdariffa in Patients with Mild to 
Moderate Hypertension: A Controlled and Randomized Clinical Trial,” Phytomedicine, Vol. 11, 2004, pp. 375382. doi:10.1016/j.phymed.2004.04.001

[14] H. H. Lin, J. H. Chen, W. H. Kuo and C. J. Wang, "Chemopreventive Properties of Hibiscus Sabdariffa L. on Human Gastric Carcinoma Cells through Apoptosis Induction and JNK/p38 MAPK Signaling Activation,” Chemico-Biological Interactions, Vol. 165, No. 1, 2007, pp. 59-75. doi:10.1016/j.cbi.2006.10.011

[15] H. H. Lin, J. H. Chen, W. H. Kuo and C. J. Wang, "Hibiscus Polyphenol-Rich Extract Induces Apoptosis in Human Gastric Carcinoma Cells via p53 Phosphorylation and p38 MAPK/FasL Cascade Pathway," Molecular Carcinogenesis, Vol. 43, No. 2, 2005, pp. 86-99. doi:10.1002/mc.20103

[16] L. T. Lin, L. T. Liu, L. C. Chiang and C. C. Lin, "In vitro Anti-hepatoma Activity of Fifteen Natural Medicines from Canada,” Phytotherapy Research, Vol. 16, No. 5, 2002, pp. 440-444. doi:10.1002/ptr.937

[17] D. X. Hou, X. Tong, N. Terahara, D. Luo and M. Fujii, "Delphinidin 3-Sambubioside, a Hibiscus Anthocyanin, Induces Apoptosis in Human Leukemia Cells through Reactive Oxygen Species-Mediated Mitochondrial Pathway," Archives of Biochemistry and Biophysics, Vol. 440, No. 1, 2005, pp. 101-109. doi:10.1016/j.abb.2005.06.002

[18] Y. C. Chang, H. P. Huang, J. D. Hsu, S. F. Yang and C. J. Wang, "Hibiscus Anthocyanins Rich Extract-Induced Apoptotic Cell Death in Human Promyelocytic Leukemia Cells," Toxicology and Applied Pharmacology, Vol. 205, No. 3, 2005, pp. 201-212. doi:10.1016/j.taap.2004.10.014

[19] T. H. Tseng, T. W. Kao, C. Y. Chu, F. P. Chou, W. L. Lin and C. J. Wang, "Induction of Apoptosis by Hibiscus Protocatechuic Acid in Human Leukemia Cells via Reduction of Retinoblastoma (RB) Phosphorylation and Bcl-2 Expression,” Biochemical Pharmacology, Vol. 60, No. 3, 2000, pp. 307-315. doi:10.1016/S0006-2952(00)00322-1

[20] H. L. Liu, W. B. Jiang and M. X. Xie, "Flavonoids: Recent Advances as Anticancer Drugs," Recent Patents on Anti-Cancer Drug Discovery, Vol. 5, No. 2, 2010, pp. 152-164. doi:10.2174/157489210790936261

[21] C. Fimognari, M. Lenzi and P. Hrelia, "Chemoprevention of Cancer by Isothiocyanates and Anthocyanins: Mechanisms of Action and Structure-Activity Relationship,” Current Medicinal Chemistry, Vol. 15, No. 5, 2008, pp. 440-447. doi:10.2174/092986708783503168

[22] L. S. Wang and G. D. Stoner, "Anthocyanins and Their Role in Cancer Prevention,” Cancer Letters, Vol. 269, No. 2, 2008, pp. 281-290. doi:10.1016/j.canlet.2008.05.020

[23] H. Fujiki, "Green Tea: Health Benefits as Cancer Preventive for Humans," Chemical Record, Vol. 5, No. 3, 2005, pp. 119-132. doi:10.1002/tcr.20039

[24] Y. Clement, "Can Green Tea Do That? A Literature Review of the Clinical Evidence," Preventive Medicine, Vol. 49, No. 2-3, 2009, pp. 83-87. doi:10.1016/j.ypmed.2009.05.005

[25] E. P. Moiseeva and M. M. Manson, "Dietary Chemopreventive Phytochemicals: Too Little or Too Much?” Cancer Prevention Research, Vol. 2, No. 7, 2009, pp. 611-616. doi:10.1158/1940-6207.CAPR-08-0102

[26] L. Orlando, P. Schiavone, P. Fedele, N. Calvani, A. Nacci, P. Rizzo, A. Marino, M. D’Amico, F. Sponziello, E. Mazzoni, M. Cinefra, N. Fazio, E. Maiello, N. Silvestris, G. Colucci and S. Cinieri, "Molecularly Targeted Endocrine Therapies for Breast Cancer," Cancer Treatment Reviews, Vol. 36, 2010, pp. S67-S71. doi:10.1016/S0305-7372(10)70023-2

[27] C. A. Lamartiniere, "Protection against Breast Cancer with Genistein: A Component of Soy," The American Journal of Clinical Nutrition, Vol. 71, No. 6, 2000, pp. 1705S-1707S.

[28] M. T. Subbiah and W. Abplanalp, "Ergosterol (Major Sterol of Baker's and Brewer's Yeast Extracts) Inhibits the Growth of Human Breast Cancer Cells in vitro and the Potential Role of Its Oxidation Products,” International Journal for Vitamin and Nutrition Research, Vol. 73, No. 1, 2003, pp. 19-23. doi:10.1024/0300-9831.73.1.19

[29] Y. H. Ju, L. M. Clausen, K. F. Allred, A. L. Almada and W. G. Helferich, "Beta-Sitosterol, Beta-Sitosterol Glucoside, and a Mixture of Beta-Sitosterol and Beta-Sitosterol Glucoside Modulate the Growth of Estrogen-Responsive Breast Cancer Cells in vitro and in Ovariectomized Athymic Mice,” Journal of Nutrition, Vol. 134, No. 5, 2004, pp. 1145-1151. 